\title{
EFFECTS OF SHORT AND LONG RUN SUBPRIME CRISIS ON THE INDUSTRIAL SECTOR IN THE EMERGING COUNTRIES: ARDL APPROACH
}

\author{
Kamel Helali ${ }^{1}$ \\ Mouna Rekik ${ }^{2}$ \\ Maha Kalai ${ }^{3}$
}

\begin{abstract}
This paper deals with the relationship between the 2007 financial crisis and the industrial sector for a panel of six emerging countries over the period 2002-2011. This crisis has spread through several transmission channels and caused many problems in the financial systems and in the economies in general. Any open economy cannot be immune from this crisis. The emerging countries are not isolated from the rest of the world and, as a result, they are affected by the negative effects of the financial crisis because of their interference with the developed economies. The effects are very clear in many real sectors mainly, in the industrial one. Our objective, in this paper, is to study the impact of the subprime crisis on the industrial sector in the emerging countries through the use of the ARDL approach so that we can derive the various short and long-run relationship between the variables question. The estimation results show that recession in the developed economies has reduced industrial production in the emerging countries through the trade channel since it suddenly limited direct investment and threatened the sectors related to the decomposition of the productive process.
\end{abstract}

Keywords: Subprime crisis, emerging countries, ARDL, short and long run effects

JEL Codes: E31, E44, F13

\section{Introduction}

The subprime crisis, erupted in the USA in summer 2007 and began to spread allover in world to become, in October 2008 the worst crisis since the Second World War. It was intensified by the lack of confidence, the shortage of liquidity, the credit crunch and the absence of transparency. It affected not only the whole U.S. economy, but also economies throughout the world. Its spread was through several transmission channels, which caused many problems for the financial systems and for the economies, in general.

The emerging countries, in which we are interested, suffered the consequences of the subprime crisis given their interdependence on the economies of the other countries. These countries are called developing countries because their economies are in a transitional phase from farming to industrialization. Although they are heterogeneous from a development perspective, they are integrated within the world economy. The impacts of the financial crisis are very clear in many of their real sectors, especially in the industry.

There is plenty of literature on the contagion phenomenon as the result of recent crises of which the influence on the emerging needs analysis (Kaminsky et al., 2003). Research has increasingly focused on the long-term effects of these crises. As a consequence, several studies analyzed the effects of financial crises on the real economy. Similarly, the study of the effect of the

\footnotetext{
${ }^{1}$ Faculty of Economics and Management of Sfax, University of Sfax, e-mail: helali.kamel @ gmail.com

${ }^{2}$ Faculty of Economics and Management of Sfax, University of Sfax, e-mail: rekikmouna70@yahoo.fr

${ }^{3}$ Faculty of Economics and Management of Sfax, University of Sfax, e-mail: helali.kalai.maha@gmail.com
} 
subprime crisis on the emerging economies, and particularly on the industrial sector, has been the subject of most of the empirical studies. De and Chiranjib (2011) attempted to analyze the impact of shocks of the global crisis on the Indian trade and industry. They used two models in their analysis: the technique of the panel data and the auto-regressive vector (VAR). The panel estimation results show that a change in the trade pattern is positively associated with a change in that of the manufacturing sector. Hence, the results of the VAR technique indicated that the change in the composition of industry was significantly reflected in the exports to the United States, Japan, and the European Union at the time of crisis. Furthermore, Al Qaisi's research (2013) aimed at investigating the effect of the global financial crisis on the industrial sector in Jordan. Various financial ratios were estimated from the financial statements of industrial firms for the period 20022008. The results show that the impact of the crisis on the industrial sector in Jordan is insignificant.

Moreover, Yilmazkuday (2008) analyzed the impact of the currency crises on the industrial sectors of Korea, Turkey and the Czech Republic. The aim behind this model is to produce probabilities for the different measures of the average growth in the industrial production through the application of Gibbs's sampling method. This showed that the effects of the currency crises will disappear in the interval of 4 years for Korea after the 1997 currency crisis, for Turkey within 7 years after the 1994 and 2001 crisis, and finally within 5 years for the Czech Republic after the 1997 currency crisis. Besides, Akingunola and Sangosanya (2011) attempted to measure the effect of the global economic crisis on the industrial performance in Nigeria. For this reason, they used a regression model to pick up the structural changes in the relationship between the macroeconomic indicators and the national industrial production before and during the crisis. The analysis revealed that industrial performance is negatively affected by external shocks.

This work is an attempt to show that the subprime crisis struck the industry in the emerging countries through multiple channels between January 2002 and December 2011. For this reason, we used the Autoregressive-Distributed Lag model (ARDL) suggested by Pesaran et al. (2001) to establish the long-run relationship of the variables.

\section{The ARDL approach}

The Autoregressive-Distributed Lag model (ARDL) on the panel data of Pesaran and al. (2001) is a method independent from the order of integration of the different variables. This model helps identify the long run relationship in an accurate way through the estimation of the dynamics of a simple equation or the focus on both the long-term relationship and the short-term dynamics. Besides, this method focuses on the variables with a different integration order. In the ARDL approach, all the variables are considered to be endogenous. The General form of this model is as follows:

$$
y_{t}=\alpha_{0}+\alpha_{1} t+\sum_{j=1}^{p} \lambda_{j} y_{t-j}+\sum_{m=0}^{q} \delta_{k}{ }^{\prime} x_{t-m}+u_{t}
$$

where $x$ represents all the regressors which are thought to be uncorrelated with the $u$ residue. The ARDL model can be presented in the following way:

$$
\Delta y_{t}=\alpha_{0}+\alpha_{1} t+\phi y_{t-1}+\beta^{\prime} x_{t}+\sum_{j=1}^{p-1} \lambda_{j}^{*} \Delta y_{t-j}+\sum_{m=0}^{q-1} \delta_{m}^{*^{\prime}} x_{t-m}+u_{t}
$$

We can formulate equation $\Delta y$ in the form an error-correction model ECM presented as follows:

$$
\Delta y_{t}=\alpha_{0}+\alpha_{1} t+\pi_{y y} y_{t-1}+\pi_{y x} x_{t-1}+\sum_{j=1}^{p-1} \Gamma_{j} \Delta Z_{t-j}+\varepsilon_{y t}
$$

with $\Pi=\left(\begin{array}{cc}\pi_{y y} & \pi_{y x} \\ \pi_{x y} & \Pi_{x x}\end{array}\right)$ the variance-covariance of $\varepsilon_{t}=\left(\varepsilon_{y t} \varepsilon_{x t}^{\prime}\right)$ and $Z_{t}=\left(y_{t} x_{t}^{\prime}\right)$. If $\phi=\pi_{y y}$ and 
$\beta=\pi_{y x . x}$, after identifying the polynomial delay in $Z$ to get the current value of $x$ in the equal part, we end up with the equation of the ARDL approach of Pesaran et al. (2001):

$$
\Delta y_{t}=\alpha_{0}+\alpha_{1} t+\pi_{y y} y_{t-1}+\pi_{y x . x} x_{t-1}+\sum_{j=1}^{p-1} \tilde{\psi}_{j}^{\prime} \Delta Z_{t-j}+\omega^{\prime} \Delta x_{t}+\varepsilon_{y t}
$$

where $\pi_{y x . x}=\pi_{y x}-\omega \Pi_{x x}, \omega=\Omega_{x x}{ }^{-1} \omega_{x y}, \Omega=\left(\begin{array}{c}\omega_{y y} \omega_{y x} \\ \omega_{x y} \Omega_{x x}\end{array}\right)$ the variance-covariance matrix of $\varepsilon_{t}$ and $u_{t}=\varepsilon_{y t}-\omega_{y x} \Omega_{x x}^{-1} \varepsilon_{x t}$.

It should be noted that the ARDL model has been incorporated to ensure that the components of $Z$ are I(1) according to the requirements of the VECM specifications. If $\phi \neq 0, \Pi$ reduced the rank to $r+1$ ( $r \leq k$, the number of variables in $Z$ ), therefore, we can express a long term relationship with $y_{t}$ as an endogenous variable, in the following way:

$$
y_{t}=\theta_{0}+\theta_{1} t-\frac{1}{\phi} \beta^{\prime} x_{t}+v_{t}
$$

The long-run relationship is non-degenerate if $\theta=-\beta / \phi$, the conditional long-term parameter vector on $x$ is not zero (or equivalent, if $\beta=0$ ). When we apply the ARDL model specification to the panel data, equation (3), written for each individual $i$ will be as follows:

$$
\Delta y_{i t}=\alpha_{0}+\alpha_{1} t+\phi_{i} y_{i t-1}+\beta_{i}^{\prime} x_{i t}+\sum_{j=1}^{p-1} \lambda_{i j}{ }^{*} \Delta y_{i, t-j}+\sum_{m=0}^{q-1} \delta_{i m}{ }^{*^{\prime}} x_{i, t-m}+u_{i t}
$$

Pesaran et al. (2001) suggest that the $u_{i t}$ residues are assumed to be independent through the individuals and the regressions of $x_{i t}$, hence, for each individual $i$, the long-term relationship is given by:

$$
y_{i t}=\theta_{0}+\theta_{1} t-\frac{\beta_{i}^{\prime}}{\phi_{i}} x_{t}+v_{i t}
$$

The general representation of the ARDL model on panel data is the following:

$\Delta y_{i t}=\alpha_{0}+\alpha_{1} t+\delta_{0} y_{i t}+\delta_{1} x_{1 i t}+\delta_{2} x_{2 i t}+\delta_{3 i t} x_{3 i t}+\sum_{i=1}^{p} \lambda_{i} \Delta y_{t-i}+\sum_{j=0}^{q_{1}} \beta_{j} \Delta x_{1 i, t-j}+\sum_{m=0}^{q_{2}} \gamma_{m} \Delta x_{2 i, t-m} \sum_{s=0}^{q_{3}} \varphi_{s} \Delta x_{3 i, t-s}+\zeta_{i t}$

The ARDL co-integration approach should consist of two stages so as to be valid as a cointegration procedure. The first step will examine the existence of a long-term relationship between the system variables. The null hypothesis assumes the lack of long run relationship between the variables $H_{0}: \delta_{0}=\delta_{1}=\delta_{2}=\delta_{3}=0$, in opposition to the alternative hypothesis $H_{1}: \delta_{0} \neq \delta_{1} \neq \delta_{2} \neq \delta_{3} \neq 0$. The procedure applied in the testing of these hypotheses is the Bounds tests which is based on F Fisher's statistic which assumes that the statistical variables in the system should be I(0) or I(1). As a result, Pesaran et al (2001) suggested two critical values for a given level of significance. If the calculated F-statistic exceeds the highest critical value, we will reject $H_{0}$. Inversely, if the value of $\mathrm{F}$ statistics is below the lower critical value, this means that there is no co-integration relationship. Finally, if the F statistic takes a value between these two critical values, we cannot conclude on this test.

The second step consists in identifying the number of lags to keep before estimating the ARDL model. The Akaike Information Criterion (AIC) and the Schwarz Bayesian Criterion (SBC) are retained here. The general representation of the error-correction model (ECM) of equation (8) is made as follows: 


$$
\Delta y_{i t}=\alpha_{0}+\alpha_{1} t+\delta E C_{i, t-1}+\sum_{i=1}^{p} \lambda_{i} \Delta y_{t-i}+\sum_{j=0}^{q_{1}} \beta_{j} \Delta x_{1 i, t-j}+\sum_{m=0}^{q_{2}} \gamma_{m} \Delta x_{2 i, t-m} \sum_{s=0}^{q_{3}} \varphi_{s} \Delta x_{3 i, t-s}+\zeta_{i t}
$$

where $\delta$ is the speed of the adjustment parameter and $E C$ the residues obtained from the estimated co-integration of equation (8). Consequently, the long-run conditional model obtained from the reduced form of equation (8) is presented in the following form:

$$
y_{i t}=\theta_{0}+\theta_{1} x_{1 i t}+\theta_{2} x_{2 i t}+\theta_{3 i t} x_{3 i t}+\mu_{i t}
$$

with $\theta_{0}=-\frac{\alpha_{0}}{\delta_{0}}, \theta_{1}=-\frac{\delta_{1}}{\delta_{0}}, \theta_{2}=-\frac{\delta_{2}}{\delta_{0}}$ and $\theta_{3}=-\frac{\delta_{3}}{\delta_{0}}$.

\section{Sample, data and integration tests}

In order to study the impact of the subprime crisis on the industrial sector of the emerging markets, we selected a sample of six countries, such as Brazil, Chile, China, Malaysia, Mexico and Turkey, extended over a period containing 120 observations. The used data cover the period between January 2002 and December 2011. The selected variables are defined as follows:

- LIPI is the natural $\log$ of the index of industrial production, which is a proxy of the industrial sector in the emerging countries.

- LCPI is the natural log of the consumer price index, which represents the price variable.

- LEXP is the natural log of exports representing the trade channel.

- SPREAD is the difference between the three-month interbank rate and that of the treasury bills. Besides, it is a sign of banks' refinancing difficulties in times of crisis. The interbank 'spread' variable is therefore a proxy of the (quantitative) liquidity problems that banks have in times of crisis and also of the financial impact.

- Volatility is the variable of the stock-market volatility, which is a proxy of the uncertainty of the global economy that affects the spending decisions of the economic agents. It is calculated by the squared residuals.

- Return is the natural log of the stock price changes, which is a proxy of the agents' total wealth. Actually, the share prices are a good sign of the wealth of various private agents (companies, households and financial institutions). Moreover, the decline in the stock prices causes difficulties in companies' funding and depreciates the balance sheets of the financial companies and institutions whose assets are valued at their market value. This situation penalizes the different investment projects.

- DU is a dummy variable representing the "crisis" variable.

\begin{tabular}{|c|c|c|c|c|c|c|c|c|c|c|}
\hline \multirow{3}{*}{ Variables } & \multicolumn{6}{|c|}{ LLC } & \multicolumn{4}{|c|}{ IPS } \\
\hline & \multicolumn{3}{|c|}{ In level } & \multicolumn{3}{|c|}{ In first difference } & \multicolumn{2}{|c|}{ In level } & \multicolumn{2}{|c|}{ In first difference } \\
\hline & $A C A T$ & $A C S T$ & $S C S T$ & $A C A T$ & $A C S T$ & $S C S T$ & $A C A T$ & $A C S T$ & $A C A T$ & $A C S T$ \\
\hline \multirow{2}{*}{ LIPI } & $-2.64^{\mathrm{a}}$ & $-2.24^{\mathrm{b}}$ & 2.45 & $-34.9^{a}$ & $-31.6^{a}$ & $-29.4^{\mathrm{a}}$ & $-5.2^{\mathrm{a}}$ & $-4.93^{a}$ & $-33.8^{a}$ & $-32.08^{a}$ \\
\hline & $(0.004)$ & $(0.012)$ & $(0.993)$ & $(0.000)$ & $(0.000)$ & $(0.000)$ & $(0.000)$ & $(0.000)$ & $(0.000)$ & $(0.000)$ \\
\hline \multirow{2}{*}{ LIPC } & $-4.11^{\mathrm{a}}$ & $-2.26^{\mathrm{b}}$ & 6.32 & $-13.4^{\mathrm{a}}$ & $-12.1^{\mathrm{a}}$ & $-10.1^{a}$ & $-4.40^{\mathrm{a}}$ & 1.24 & $-13.6^{a}$ & $-13.9^{a}$ \\
\hline & $(0.000)$ & $(0.011)$ & $(1.000)$ & $(0.000)$ & $(0.000)$ & $(0.000)$ & $(0.000)$ & $(0.894)$ & $(0.000)$ & $(0.000)$ \\
\hline \multirow{2}{*}{ LEXP } & -0.46 & $-2.81^{\mathrm{a}}$ & 3.99 & $-26.0^{\mathrm{a}}$ & $-24.41^{a}$ & $-30.2^{\mathrm{a}}$ & $-1.46^{c}$ & -0.59 & $-27.8^{a}$ & $-26.7^{a}$ \\
\hline & $(0.319)$ & $(0.002)$ & $(1.000)$ & $(0.000)$ & $(0.000)$ & $(0.000)$ & $(0.071)$ & $(0.276)$ & $(0.000)$ & $(0.000)$ \\
\hline \multirow{2}{*}{ SPREAD } & $-6.48^{a}$ & $-4.69^{a}$ & $-4.31^{\mathrm{a}}$ & $-33.4^{\mathrm{a}}$ & $-30.1^{a}$ & $-28.1^{a}$ & $-6.94^{\mathrm{a}}$ & $-6.14^{\mathrm{a}}$ & $-28.5^{\mathrm{a}}$ & $-27.6^{\mathrm{a}}$ \\
\hline & $(0.000)$ & $(0.000)$ & $(0.000)$ & $(0.000)$ & $(0.000)$ & $(0.000)$ & $(0.000)$ & $(0.000)$ & $(0.000)$ & $(0.000)$ \\
\hline \multirow{2}{*}{ Volatility } & $-20.4^{a}$ & $-18.4^{\mathrm{a}}$ & $-17.4^{\mathrm{a}}$ & $-20.9^{a}$ & $-19.7^{a}$ & $-25.8^{a}$ & $-17.3^{a}$ & $-17.3^{\mathrm{a}}$ & $-27.6^{a}$ & $-26.9^{a}$ \\
\hline & $(0.000)$ & $(0.000)$ & $(0.000)$ & $(0.000)$ & $(0.000)$ & $(0.000)$ & $(0.000)$ & $(0.000)$ & $(0.000)$ & $(0.000)$ \\
\hline \multirow{2}{*}{ Return } & $-21.2^{\mathrm{a}}$ & $-19.3^{\mathrm{a}}$ & $-20.8^{a}$ & $-13.0^{\mathrm{a}}$ & $-13.0^{\mathrm{a}}$ & $-28.1^{a}$ & $-20.5^{\mathrm{a}}$ & $-20.3^{a}$ & $-28.5^{\mathrm{a}}$ & $-27.7^{a}$ \\
\hline & $(0.000)$ & $(0.000)$ & $(0.000)$ & $(0.000)$ & $(0.000)$ & $(0.000)$ & $(0.000)$ & $(0.000)$ & $(0.000)$ & $(0.000)$ \\
\hline
\end{tabular}

The results of the unit root tests

Source: Created by the authors based on the results. (a), (b) and (c) show significance respectively at $1 \%, 5 \%$ and $10 \%$. AC: with a constant, SC: without a constant, AT: with a trend, ST: with a trend. The p-value in (.). 
Before estimating our basic model, we found it necessary to test the stationarity of the selected variables. In fact, we refer to the tests of Levin, Lin and Chu (2002) (LLC) and Im, Pesaran and Shin (2003) (IPS) who advocate the hypothesis of no autocorrelation of the residuals. Table no. 1 shows the different results obtained in our panel data unit root tests LLC and IPS.

The LLC and IPS tests help conclude that the IPI, CPI and EXP variables are not stationary in levels. The tests indicate that these three variables are integrated of order 1, whereas the variables SPREAD, Return and Volatility are stationary in level. These tests concluded the rejection of the unit root null hypothesis. Therefore, these variables are integrated of order 0 . Nevertheless, all the variables are stationary in first differences. In this regard, we will test for the existence of one or more co-integrating relationships between the concerned variables. According to the results of the panel unit root tests, the co-integration tests on the heterogeneous panel data developed by Pedroni (2004) aimed to understand the idea of no co-integration in the null hypothesis, both for the heterogeneous and homogeneous panels. Table no. 2 shows the results of Pedroni's (2004) cointegration test.

Table no. 2

The results of Pedroni's co-integration test (2004)

\begin{tabular}{lccc}
\hline Statistics & $\boldsymbol{A T A C}$ & $\boldsymbol{S T A C}$ & $\boldsymbol{S T S C}$ \\
\hline V-statistical panel & -0.478 & 0.741 & -1.629 \\
& $(0.683)$ & $(0.229)$ & $(0.948)$ \\
Rho- Statistical panel & $-8.089^{* * *}$ & $-7.813^{* * *}$ & $-1.533^{* * *}$ \\
& $(0.000)$ & $(0.000)$ & $(0.062)$ \\
PP- Statistical panel & $-8.238^{* * *}$ & $-7.396^{* * *}$ & $-2.448^{* * *}$ \\
& $(0.000)$ & $(0.000)$ & $(0.007)$ \\
ADF- Statistical panel & $-1.279^{*}$ & $-1.823^{* *}$ & -0.227 \\
& $(0.097)$ & $(0.034)$ & $(0.410)$ \\
Rho- Statistical group & $-8.991^{* * *}$ & $-9.158^{* * *}$ & $-1.297^{*}$ \\
& $(0.000)$ & $(0.000)$ & $(0.097)$ \\
PP- Statistical group & $-8.987^{* * *}$ & $-8.883^{* * *}$ & $-2.564^{* * *}$ \\
& $(0.000)$ & $(0.000)$ & $(0.000)$ \\
ADF- Statistical group & $-2.924^{* * * *}$ & $-2.189^{* *}$ & -0.382 \\
& $(0.001)$ & $(0.014)$ & $(0.351)$ \\
\hline Source: Created by the authors based on the results. ${ }^{*},{ }^{* *},{ }^{* * *}$ Significance at & $10 \%, 5 \%$, and $1 \%$.
\end{tabular}

It is clear, from the various test statistics of Pedroni, that there is at least one co-integrating relationship checked by one of the seven test statistics. Actually, the "Panel PP-Statistics" managed to outperform the three models. To gain a better understanding of the above result, we have preferred to add a second test to confirm or rule out the existence of this co-integrating relationship. This test is the one of Westerlund (2007). Indeed, the results of the four statistics of this test are presented in Table no. 3 where the $G a$ and $P a$ statistics support the existence of a co-integration relationship.

The results of Westerlund's co-integration test (2007)

\begin{tabular}{lcc}
\hline Statistics & Coefficients & P-value \\
\hline $\mathrm{Gt}$ & -2.995 & 0.185 \\
$\mathrm{Ga}$ & $\mathbf{- 2 1 . 2 2 3}$ & $\mathbf{0 . 0 3 2}^{* * *}$ \\
$\mathrm{Pt}$ & -6.889 & 0.160 \\
$\mathrm{~Pa}$ & $\mathbf{- 1 8 . 0 3 9}$ & $\mathbf{0 . 0 2 4}$ \\
\hline
\end{tabular}

Source: Created by the authors based on the results. 
basic model.

In general, we can say that there is a co-integrating relationship between the variables of the

Results of the ARDL approach in panel and interpretations

Empirical analysis reveals that the results of the F-statistic support the model with Dummy (01/02/2009) and no tendency to at least $99 \%$. The results in Table no. 4 indicate that the null hypothesis of no long-term relationship can be rejected. Therefore, there is a long-term relationship between the model variables when the high value of Fisher's F statistic (22.39) is much higher than the critical value for $k=5$ (4.015 at 5\%) as it was found by Narayan (2005). Indeed, the maximum number of lags is equal to 1 .

Since there is a long-run relationship, we use the ARDL co-integration method for the equation parameters for a number lags equal to 1 . In order to find the optimal order of the long run variables levels, we choose both the AIC and SBC criteria as well as Fisher's maximum value which led to the $(1,0,0,0,0,0)$ ARDL model.

Table no. 4

Estimation of the short-run ARDL model

\begin{tabular}{|c|c|c|}
\hline \multicolumn{3}{|c|}{$\mathrm{p}=1 ; \mathrm{F}=22.39>4.015^{\mathrm{a}} ; \mathrm{AIC}=-4.589 ; \mathrm{SBC}=-4.499$} \\
\hline Variables & $\operatorname{ARDL}(\mathbf{1 , 0 , 0 , 0 , 0 , 0 )}$ & ECM_ARDL(1,0,0,0,0,0) \\
\hline $\mathrm{Y}_{\mathrm{t}-1}$ & $\begin{array}{c}-\mathbf{- 0 . 4 6 9} 9^{* * * *} \\
(\mathbf{0 . 0 0 0})\end{array}$ & $e_{0}$ \\
\hline $\mathrm{X}_{1 \mathrm{t}-1}$ & $\begin{array}{c}0.139^{* * * *} \\
(0.000)\end{array}$ & - \\
\hline $\mathrm{X}_{2 \mathrm{t}-1}$ & $\begin{array}{c}\mathbf{0 . 0 2 2}^{* * * *} \\
(0.000)\end{array}$ & - \\
\hline $\mathrm{X}_{3 \mathrm{t}-1}$ & $\begin{array}{l}-0.000 \\
(0.777)\end{array}$ & - \\
\hline $\mathrm{X}_{4 \mathrm{t}-1}$ & $\begin{array}{l}-0.000 \\
(0.623)\end{array}$ & - \\
\hline $\mathrm{X}_{5 \mathrm{t}-1}$ & $\begin{array}{c}0.000 \\
(0.524)\end{array}$ & - \\
\hline$\Delta \mathrm{Y}_{\mathrm{t}-1}$ & $\begin{array}{c}-0.257^{* * * *} \\
(0.000)\end{array}$ & $\begin{array}{l}0.024^{*} \\
(0.061)\end{array}$ \\
\hline$\Delta \mathrm{X}_{1 \mathrm{t}}$ & $\begin{array}{c}0.230 \\
(0.506)\end{array}$ & $\begin{array}{l}0.229^{* * *} \\
(0.049)\end{array}$ \\
\hline$\Delta \mathrm{X}_{2 \mathrm{t}}$ & $\begin{array}{c}\mathbf{0 . 0 6 3}^{* * *} \\
(0.046)\end{array}$ & $\begin{array}{l}\mathbf{0 . 0 6 8}^{* *} \\
(\mathbf{0 . 0 2 9})\end{array}$ \\
\hline$\Delta \mathrm{X}_{3 \mathrm{t}}$ & $\begin{array}{l}-0.000 \\
(0.860)\end{array}$ & $\begin{array}{l}-7.107 \\
(0.797)\end{array}$ \\
\hline$\Delta \mathrm{X}_{4 \mathrm{t}}$ & $\begin{array}{c}0.000 \\
(0.920)\end{array}$ & $\begin{array}{l}1.935 \\
(0.799)\end{array}$ \\
\hline$\Delta \mathrm{X}_{5 \mathrm{t}}$ & $\begin{array}{c}0.000 \\
(0.495)\end{array}$ & $\begin{array}{c}2.324 \\
(0.580)\end{array}$ \\
\hline Constant & $\begin{array}{l}1.309^{* * *} \\
(0.000)\end{array}$ & $\begin{array}{l}1.329^{* * *} \\
(0.003)\end{array}$ \\
\hline DUM & $\begin{array}{l}-0.084^{* * *} \\
(0.040)\end{array}$ & $\begin{array}{l}-\mathbf{- 0 . 0 8 7}^{* * *} \\
(\mathbf{0 . 0 2 9})\end{array}$ \\
\hline $\mathrm{EC}_{\mathrm{t}-1}$ & - & $\begin{array}{c}-0.815^{* * * *} \\
(0.000)\end{array}$ \\
\hline
\end{tabular}

Source: Created by the authors based on the results. $Y$ : IPI; $X_{1}$ : CPI; $X_{2}$ : Exports; $X$ : SPREAD interbank; $X_{4}$ : Volatility of stock price; $X_{5}$ : Return on equity prices; DUM: dummy variable. a: see Narayan (2005: 1988). 
Table no. 4 above shows the results of the short run ARDL model estimation $(1,0,0,0,0,0)$. The results reveal the significance of some variables for a $1 \%$ risk. The estimation of the errorcorrection model, which is marked by ECM_ARDL, is represented in order so as to perform the stability test on the coefficients and on the variability of the model.

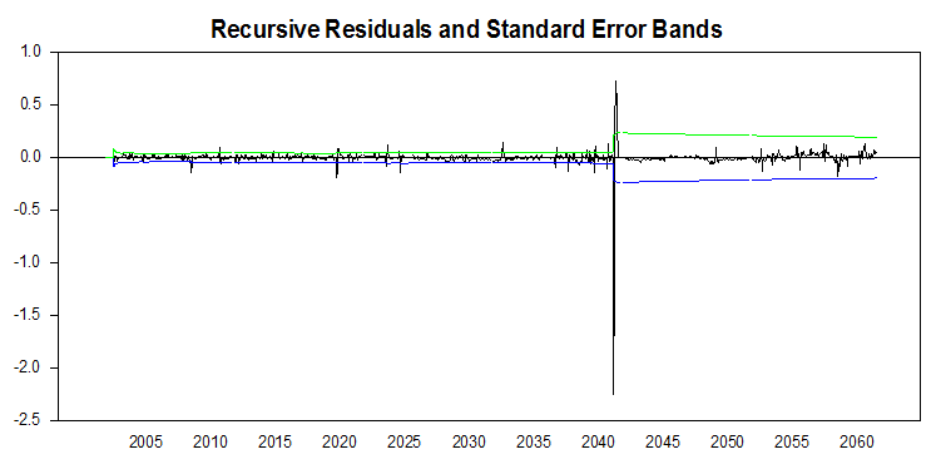

Figure no. 1 - Recursive residues and standard deviation range

Source: Created by the authors based on the results.

The results indicate that the error-correction term, $\mathrm{EC}_{\mathrm{t}-1}$, is statistically significant and negative, which clearly shows the co-integration relationship between the variables in the model. More precisely, the estimated value of $\mathrm{EC}_{\mathrm{t}-1}$, which is equal to -0.815 , means that the adjustment of the long run equilibrium in response to the imbalance caused by the short run impact of the previous period of speed is of $81.5 \%$.

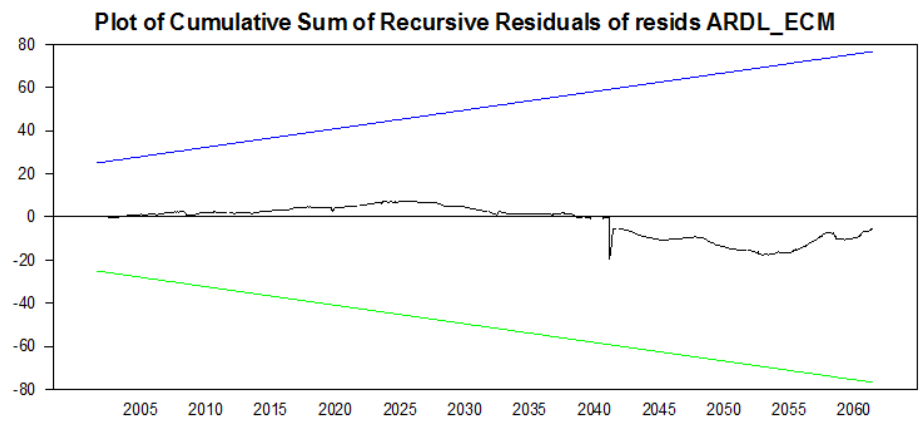

Figure no. 2 - Representation of the ECM_ARDL residue cumulative sum

Source: Created by the authors based on the results.

Figure no. 1 shows the evolution of the recursive estimation residues of the ECM_ARDL model within the limit values. This estimation is useful for the identification of the statistics of the cumulative sums of the recursive residues (CUSUM) and that of the recursive squared residues (CUSUMQ) and of their limit values. Furthermore, Figures no. 2 and no. 3 show the model stability for a confidence level of $95 \%$.

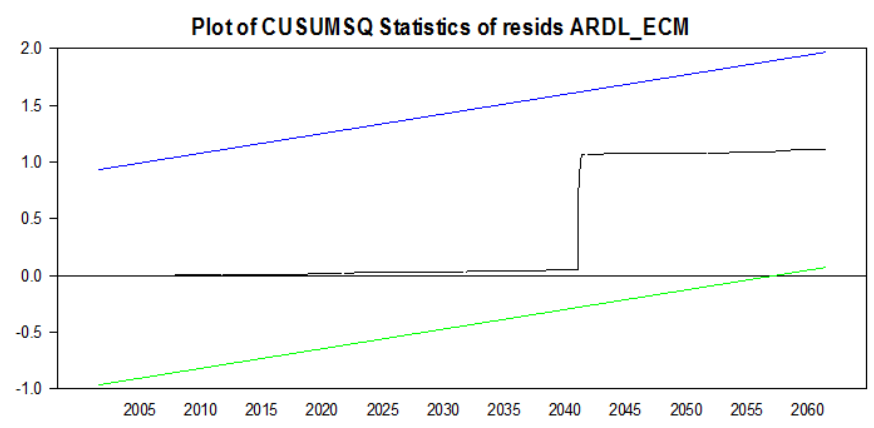

Figure no. 3 - Representation of the cumulative sum of squares of the ECM_ARDL residues Source: Created by the authors based on the results. 
At the level of the long run results, variables $X_{1}, X_{2}, X_{3}$ and $X_{4}$ are statistically significant at $5 \%$. This shows that there is a positive relationship between the IPI and the $C P I$ and EXP variables, and a negative relationship between the IPI and the SPREAD variables and the long-run volatility in this sample of six emerging countries. Moreover, we recorded a significant and negative effect of the dummy variable on the index of industrial production for all the countries of the sample. Consequently, the long run model estimated equation can be written as follows:

$$
\begin{aligned}
& \underset{\left(t_{-} \text {stat }\right)}{\operatorname{Ln} I \hat{P}}{ }_{t}=\underset{(10.806)}{2.787}+\underset{(5.175)}{0.297} \operatorname{Ln} C P I_{t}+\underset{(5.552)}{0.048} \operatorname{Ln} E X P-\underset{(-2.827)}{0.001} \operatorname{Ln} S P R E A D-\underset{(-4.914)}{1.10} e^{-5} \text { Ln Volatilty } \\
& \quad+\underset{(0.633)}{0.001} \operatorname{Ln} \operatorname{Re} \text { turns }-\underset{(-2.179)}{0.087} D U M
\end{aligned}
$$

By referring to this equation, we can say that the subprime crisis may affect industry in the emerging countries through several channels, namely the consumer prices, the trade channel (Exports), the financial channel and the economic uncertainty. Our results show that the consumer price index and exports are statistically significant for the industrial sector of the emerging economies in the long run. In fact, the subprime crisis led to the shrinking of the trade and global demand in the advanced economies, which affected the exporting capacities of the developing countries and greatly deteriorated industrial production in these countries.

For this reason, industrial production in these countries is affected by the negative sign of the interbank spread and price volatility. Furthermore, the emerging economies that are highly integrated into the global financial markets have seen their stock indices drop and stock market uncertainty rise. Therefore, volatile stock prices collapse and credit becomes scarce. These turbulences in the financial and equity markets have a negative effect on the industrial production in these countries. Based on our long-term estimates, we can actually say that the estimated coefficient of the dummy variable is negative and statistically significant. This implies that the subprime crisis has negatively and deeply affected the industrial sector in the emerging countries.

To sum up, we can say that recession in the industrial economies, which initially reduced the exports of the emerging countries, was transmitted, firstly through the trade channel, then the financial one since it largely reduced direct investment and threatened the sectors related to the decomposition of the productive process (automatic textile, aerospace, ...). The drop in the worldwide demand led to the collapse of the car and construction market.

\section{Conclusions}

By looking at the results of the ARDL approach, we can say that the subprime crisis has great impact on the industrial sector in the emerging countries through four channels, namely the effect of the consumer price index, the trade channel (Exports), the financial channel and the economic uncertainty. Finally, we can conclude that this study focuses on the importance of the trade channel in the transmission of the financial crisis to the industrial sector of the emerging countries. Actually, all the studied emerging countries are specialized in the industrial sector and therefore depend on the foreign demand (especially from the developed countries). Therefore, we can assume that the fall of exports in these countries has a significant effect on the deterioration of industrial production in almost all the countries. Thus, these countries are expected to take political and economic measures to mitigate the negative effects of the subprime crisis on economic growth.

It seems then appropriate to include in our study more information variables connected with the real economy. Besides, it was necessary to take into account the intra-regional effects that have certainly played an important role in the spread of the crisis. 


\section{References}

1. Akingunola R. O., Sangosanya A. O., 2011. Global financial crisis and industrial sector performance in Nigeria: A structural analysis, European Journal of Humanities and Social Sciences, Vol. 3, No. 1, pp. 66-81

2. Al Qaisi K., 2013. The effect of the financial crisis on the Jordanian industrial sector, International Journal of Finance and Banking Studies, Vol. 2, No. 1, pp. 43-47

3. De P., Chiranjib N., 2011. Global financial crisis: Implications for trade and industrial restructuring in India, ADBI Working Paper Series

4. Im K. S., Pesaran M. H., Shin Y., 2003. Testing for unit roots in heterogeneous panels, Journal of Econometrics, Vol. 115, pp. 53-74, Elsevier

5. Kaminsky G. L., Reinhart C., Vegh C., 2003. The Unholy Trinity of Financial Contagion, NBER Working Paper, No. 10061

6. Levin A., Lin C. F., Chu C., 2002. Unit root tests in panel data: asymptotic and finitesample properties, Journal of Econometrics, Vol. 108, pp. 1-24

7. Narayan, P. K., 2005. The saving and investment nexus for China: Evidence from cointegration tests, Applied Economics, Vol. 37, pp. 1979-1990

8. Pedroni, P., 2004. Panel cointegration: asymptotic and finite sample properties of pooled time series tests with an application to the PPP hypothesis: new results, Econometric Theory, Vol. 20, pp. 597-627

9. Pesaran M. Hashem, Shin Y., Smith R. J., 2001. Bounds Testing Approaches to the Analysis of Level Relationships, Journal of Applied Econometrics, Vol. 16, pp. 289-326

10. Westerlund J., 2007. Testing for error correction in panel data, Oxford bulletin of economics and statistics, Vol. 69, No. 6, pp. 709-748

11. Yilmazkuday H., 2008. The effects of currency crises in emerging markets on the industrial sector: An Alternative Regime-Shifting Approche, Emerging Markets Finance and Trade, Forthcoming. Florida International University, Vol. 7, No. 1, pp. 1-4 